\title{
A Review on Stem cell Research \& Their Role in Various Diseases
}

\author{
Arun Kumar $\mathbf{R}^{1 *}$, Sathish Kumar $\mathrm{D}^{2}$ and Nishanth $\mathrm{T}^{1}$ \\ ${ }^{1}$ Department of Biochemistry \& Bioinformatics, Gitam Institute of Science, GITAM University, Visakhapatnam, India
}

${ }^{2}$ Department of Biotechnology, University of Hyderabad, Hyderabad, India

\begin{abstract}
Stem cells likely play key roles in the repair of diverse injuries or disorders in body. Recent advances in biotechnology and regenerative medicine brought a revolutionary change in the practice of medicine. Advancements in stem cell biology, including embryonic and postnatal somatic stem cells, have made the prospect of tissue regeneration a potential clinical reality. Absolute concept for the use of stem cells in bone disorders has been centered on the strategies for reconstructing segmental regions of the skeleton, lost to trauma or surgery, and in muscle diseases, to provide normal population of cells in order to replace defective tissue.
\end{abstract}

Keywords: Stem cells; Cancer; Diabetes; Insulin; Multipotent stem cells; Immunodeficiency; Cancer stem cells; Bone and Cartilage

Abbreviations: ES: Embryonic Stem; IPSCS: Induced Pluripotent Stem Cells; CSC: Cancer Stem Cells; BCRP: Breast Cancer Resistance Protein; VEGF: Vascular Endothelial Growth Factor; HCC: Hepatocellular Carcinoma; BBB: Blood-Brain Barrier; CNS: Central Nervous System; GVHD: Graft-Versus-Host Disease

\section{Introduction}

Stem cells have potential to develop into many different cell types in the body i.e., Stem cells [1] are distinguished generally by their ability to differentiate into many types of cells in the body and to self-replicate indefinitely during early life and growth. Stem cells [2] in many tissues serve as a sort of internal repair system, dividing essentially without limit to replenish other cells as long as the person or animal is still alive. Stem cells [3] are capable of dividing and renewing themselves for long periods unlike muscle cells, blood cells, or nerve cells which do not normally replicate themselves stem cells [4] may replicate many times, or proliferate. A starting population of stem cells that proliferates for many months in the laboratory can yield millions of cells. If the resulting cells continue to be unspecialized, like the parent stem cells, the cells are said to be capable of long-term self-renewal [5].

Particularly Neural stem cells exist not only in the developing mammalian nervous system but also in the adult nervous system of all mammalian organisms, including humans. Neural stem cells can also be derived from more primitive embryonic stem cells. The location of the adult stem cells and the brain regions to which their progeny migrate in order to differentiate remain unresolved, although the number of viable locations is limited in the adult. Potential uses of stem cells [6] in repair include transplantation to repair missing cells and the activation of endogenous cells to provide "self-repair" [7].

Multipotent stem cells have the same basic features of all stem cells. As with all stem cells [8] multipotent stem cells are unspecialized cells that have the ability to: Self-renew for long periods of time and differentiate into specialized cells with specific functions. A multipotent stem cell can give rise to other types of cells but it is limited in its ability to differentiate. Multipotent stem cells include those in the brain that give rise to different neural cells and glia or hematopoietic cells [9], which can give rise to different blood cell types, but they can't create brain cells. Bone marrow also contains multipotent stem cells that give rise to all blood cell types but not other cells [10].
In general stem cells [11] are classified in three types. They are

- Embryonic stem cells,

- Adult or somatic stem cells,

- Induced pluripotent stem cells or iPSCs.

\section{Embryonic stem cells}

Embryonic stem (ES) cells are derived from totipotent cells of the early mammalian embryo and are capable of unlimited, undifferentiated proliferation in vitro [12].

\section{Adult or somatic stem cells}

Adult stem cells are stem cells [13] that can be derived from different parts of the body and, depending on where they are from, have different properties. They exist in several different tissues including bone marrow, blood and the brain [14].

\section{Induced pluripotent stem cells or iPSCs}

Induced Pluripotent stem cells are often termed 'true' stem cells [15] because they have the potential to differentiate into almost any cell in the body. This means the induced pluripotent stem cells (iPSCs) from somatic cells demonstrates that adult mammalian cell scan be reprogrammed to a pluripotent state by the enforced expression of a few embryonic transcription factors [16]

\section{Stem cell application in medicine}

Human stem cell [17] research holds an enormous potential to contribute the understanding of fundamental human biology. The introductions of antibiotics and vaccines, for example, have dramatically increased life spans and improved the health of people

*Corresponding author: Arun Kumar R, Department Of Biochemistry, Gitam Institute of Science, Gitam University, Visakhapatnam, India, E-mail: arunram88@ gmail.com

Received October 14, 2011; Accepted November 12, 2011; Published November 14,2011

Citation: Arun Kumar R, Sathish Kumar D, Nishanth T (2011) A Review on Stem cell Research \& Their Role in Various Diseases. J Stem Cell Res Ther 1:112. doi:10.4172/2157-7633.1000112

Copyright: ( 2011 Arun Kumar R, et al. This is an open-access article distributed under the terms of the Creative Commons Attribution License, which permits unrestricted use, distribution, and reproduction in any medium, provided the original author and source are credited. 
all over the world. The science of stem cell therapies, potentially as important as these other advances, is about to enter a phase of research and development that could lead to unprecedented cures and palliative treatments. Some Examples of Treatments for Major Diseases are like Cancer, Type 1 Diabetes in Children, Nervous System Diseases, Primary Immunodeficiency Diseases, Diseases of Bone and Cartilage [18].

\section{Stem cells in Cancer}

The term "cancer" describes a group of diseases that are characterized by uncontrolled cellular growth, cellular invasion into adjacent tissues, and the potential to metastasize if not treated at a sufficiently early stage [19].

These tumor-forming cells could hypothetically originate from stem, progenitor, or differentiated cells. Several characteristics of the leukemia-initiating cells support the stem cell [20] origin hypothesis [21]. Cancer cells arise from Stem Cells [22]. Stem cells are distinguished from other cells by two characteristics: They can divide to produce copies of themselves, or self-renew, under appropriate conditions and they are pluripotent, or able to differentiate into most, if not all, mature cell types [23]. The differentiation pathway from a stem cell [24] to a differentiated cell usually involves one or more intermediate cell types. These intermediate cells, which are more abundant in adult tissue than are stem cells [25], are called progenitor or precursor cells. They are partly differentiated cells present in fetal and adult tissues that usually divide to produce mature cells. However, they retain a partial capacity for self-renewal [26].

Cancer Stem Cells [27] could support metastasis [28-30]. Metastasis [31-33] is a complex, multi-step process that involves a specific sequence of events; namely, cancer cells must escape from the original tumor, migrate through the blood or lymph to a new site, adhere to the new site, move from the circulation into the local tissue, form micro metastases, develop a blood supply, and grow to form macroscopic and clinically relevant metastases [34].

Recent studies in solid tumors indicate that the concept of cancer as a hierarchy initiated and maintained by a rare population of stem cells [35] may have larger implications beyond haematopoiesis field. Identification in the previous years of breast cancer [36,37] stem cells and characterization of central nervous system stem cells [38] responsible for the maintenance of some brain tumors have increased the evidence of the veracity of rare cancer stem cells that drive the formation of a number of different tumors types, raising the question of whether all cancers originate from and are maintained by cancer stem cells.

Breast cancer stem cells (CSC) $[39,40]$ have been postulated for failure of breast cancer [41,42] treatment. Breast CSCs with respect to their mechanism of resistance to conventional therapy, in molecular biology developed treatment strategies that may improve survival of breast cancer $[43,44]$ patients. This was proved by many literatures in in vitro and in vivo studies of breast CSCs. Breast CSCs over express breast cancer [45-47] resistance protein (BCRP) which allows cancer cells to transport actively chemotherapy agents out of the cells [48].

Skin squamous cell carcinomas [49] are the most frequent cancers. Skin squamous cell carcinoma [50,51] like many other human cancers, contain particular cancer cells known as cancer stem cells [52,53] which are present in increased self-renewal potential that sustain tumor growth[54].

Vascular endothelial growth factor (VEGF) a molecule known to regulate the formation of new vessels is expressed at high level by skin cancer stem cells, which are located in close contact to the blood vessels. VEGF and its receptors have been developed to inhibit angiogenesis in cancer [55] patients. Angiogenesis is critical during tumor initiation and malignant progression [56].

In adults Hepatocellular carcinoma (HCC) is the most common carcinoma [57] or primary malignancy of the liver. The hypothetical involvement of stem cells [58] as tumor progenitor cells led to the idea that cancer should be treatable by forcing the differentiation of cancer transit-amplifying cells [59]. Hepatocytes in normal adult liver have a lifespan of over a year. In response to parenchymal cell loss, the hepatocytes restore the liver mass by self-replication. Hepatocytes are directly involved in carcinogenesis of Hepatocellular carcinoma [60]. Liver stem cells $[61,62]$ harvested from the bone marrow can further augment and accelerate the liver's natural capacity to regenerate itself. Although the liver $[63,64]$ can regenerate in the body, liver failure caused by diseases like cirrhosis and cancers eventually destroy the liver's regenerative ability $[65,66]$.

\section{Stem cells in Type 1 Diabetes in Children}

Type 1 diabetes $[67,68]$ is an autoimmune disorder characterized by T-cell- mediated destruction of insulin $[69,70]$ producing cells and lifelong dependence on exogenous insulin [71] administration seen both in children and adults. The majority of efforts seeking to ameliorate the autoimmune process and reverse hyperglycemia have focused on the use of immunosuppressive or immunomodulatory drugs [72]. Type 1 diabetes $[73,74]$ accounts for only about $5-10 \%$ of all cases of diabetes; however, its incidence continues to increase worldwide and it has serious short-term and long-term implications. The disorder has a strong genetic component, inherited mainly through the HLA complex, but the factors that trigger onset of clinical disease remain largely unknown. General complications for Type 1 Diabetes [75,76] consist of microvascular and macrovascular disease, which account for the major morbidity and mortality associated with type 1 diabetes [77].

Recently biological therapies for type 1 diabetes [78] had emerged from the forefront of stem cell and islet cell biology variety of mechanisms by which natural regeneration of pancreatic islet cells occurs, despite the underlying autoimmune defect. Two mechanisms in particular, $\beta$-islet cell proliferation and stem cell differentiation can be tackled in some innovative ways in order to regenerate islets lost to disease potential biological therapies for type 1 diabetes [79], including the use of adult stem cells from the spleen, an organ not previously considered a source of pancreatic stem cells. Stem cells of the spleen have been demonstrated to home to the pancreas, where they mature into fully functional islet cells responsible for restoring normoglycemia. If the underlying autoimmune defect can be eradicated, stem cells of the spleen can be used to regrow islets destroyed by type 1 diabetes [80].

\section{Stem cells in Nervous System Diseases}

Many nervous system diseases result from loss of nerve cells. Mature nerve cells cannot divide to replace those that are lost. Thus, without a "new" source of functioning nerve tissue, no therapeutic possibilities 
exist. In Parkinson's disease, nerve cells that make the chemical dopamine die. In Alzheimer's disease, cells that are responsible for the production of certain neurotransmitters die. In amyotrophic lateral sclerosis, the motor nerve cells that activate muscles die. In spinal cord injury, brain trauma, and even stroke, many different types of cells are lost or die. In multiple sclerosis, glia, the cells that protect nerve fibers are lost. Perhaps the only hope for treating such individuals comes from the potential to create new nerve tissue restoring function from pluripotent stem cells $[81,82]$.

Bone marrow stem cells are capable of differentiating into multiple cell types, they can migrate across the blood-brain barrier (BBB) in many regions of the Central Nervous System (CNS). The generation of these cells during adulthood doesn't only depend on proliferation of resident cells. Bone marrow-derived stem cells in the brain mostly differentiate into perivascular microglia and rarely cross the BBB [83].

In regenerative medicine, stem cells [84] are currently considered as ideal for the treatment of diseases and injuries of the nervous system. The general principle involved is that the replacement of damaged cells and the restoration of function that can be accomplished by the transplantation of embryonic or adult stem cells [85]. Advancements in stem cell biology were recently propelled by the ability to generate induced pluripotent stem (iPS) cells from fibroblasts of several neurodegenerative diseases. The general examples are Parkinson's and Huntington's diseases, Amyotrophic Lateral Sclerosis and Spinal Muscular Atrophy [86].

\section{Stem cells in Primary Immunodeficiency Diseases}

Primary cellular immunodeficiencies are a group of inherited disorders characterized by severe impairment of the innate or adaptive immune systems, which generally leads to early death from infectious complications. Immunodeficiency, often associated with malignant proliferation of the lymphoid system i.e., myeloma, chronic lymphatic leukemia, Hodgkin's disease. Hematopoietic stem cell [87] transplantation is the definitive therapy for a variety of rare primary cellular immunodeficiency syndromes diagnosed particularly in children. All primary immunodeficiencies benefit from early diagnosis and transplantation before the development of serious infections, which contribute to a significant increased risk of mortality following transplant [88]. Bone marrow transplantation can ameliorate severe combined immunodeficiency. Severe Combined Immunodeficiency is a rare, fatal syndrome that can be due to a variety of genetic abnormalities causing profound deficiencies of lymphocytes [89].

Lethal graft-versus-host disease (GVHD) was a major problem when marrow from HLA-mismatched donors was transplanted. The defect in infants with severe combined immunodeficiency is immunologic rather than hematologic, and because these infants cannot reject allografts, successful marrow transplantation for the treatment of this disease does not require chemotherapeutic conditioning before transplantation. Moreover, prophylaxis against GVHD is not necessary after transplantation of HLA-identical marrow or T-cell-depleted haploidentical marrow [90].

\section{Stem cells in Diseases of Bone and Cartilage}

Cell-based bone and cartilage replacement is an evolving therapy aiming at the treatment of humans who suffer from limb amputation, damaged tissues and various bone and cartilage-related disorders. Stem cells [91] are undifferentiated cells with the capability to regenerate into one or more committed cell lineages [92]. Once Stem cells are appropriately differentiated they could correct many diseases and degenerative conditions in which bone or cartilage cells are deficient in numbers or defective in function which can be used for treatment of genetic disorders such as osteogenesis imperfecta and chondrodysplasias [93]. Mesenchymal stem cells have been identified in bone marrow as non-hematopoietic stem cells that may differentiate in to tissues of mesodermal origin such as adipocytes [94,95] ostoblasts, stromal cells, and chondrocytes. These cells can differentiate in to tissues of ectodermal and endodermal origin such as hepatocytes [96]. These mesenchymal stem cells [97] are considered as regenerative medicine for bone repair, cartilage repair, tendon and skeletal muscle repair [98] which have great potential in the field of tissue engineering and regenerative medicine where cartilage and bone conditions which are non-treatable or show very slow improvement can be effectively handled [99]. The post-natal bone marrow has been seen as an organ composed of two main systems one is the hematopoietic tissue proper and the other is associated supporting stroma [100].

\section{Conclusion}

Stem cells have the ability to differentiate into many types of cells in the body and to self-replicate indefinitely during early life and growth. Stem cell can self-renew for long periods of time and differentiate into specialized cells with specific functions. A multipotent stem cell can give rise to other types of cells but it is limited in its ability to differentiate. The benefits to individuals and to society gained by the introduction of new drugs or medical technologies are difficult to estimate. The introductions of antibiotics and vaccines had increased life span and improved the health of people all over the world. Despite these and other advances in the prevention and treatment of human diseases such as heart disease, diabetes, cancer, and diseases of the nervous system such as Alzheimer's disease present continuing challenges to the health and well-being of people everywhere. The science leading to the development of techniques for culturing human stem cells could lead to unprecedented treatments and even cures for these and other diseases.

\section{References}

1. Minguell JJ, Pereira A, Bartholomew P and Lasala GP (2011) The Intrathecal Infusion of Mesenchymal Stem Cells into Healthy Rabbits is Safe and Devoid of Neurological or Clinical Complications. J Stem Cell Res Ther 1: 104.

2. Cruz M, Siden A, Tasat DR, Yakisich JS (2010) Are all Glioma Cells Cancer Stem Cells? J Cancer Sci Ther 2: 100-106.

3. Duran JM, George JC (2011) A Review of the Basis of Autologous Stem Cell Therapy for Coronary Artery Disease. J Clinic Experiment Cardiol 2: 130.

4. Rameshwar P (2011) Post-identification of Cancer Stem Cell: Ethical and Scientific Dilemmas in Therapeutic Development?. J Stem Cell Res Ther 1 e101.

5. http://stemcells.nih.gov/info/basics/basics3.asp

6. Novik AA, Kuznetsov AN, Melnichenko VY, Fedorenko DA, Ionova TI et al. (2011) Non-myeloablative Autologous Haematopoietic Stem Cel Transplantation with Consolidation Therapy using Mitoxantrone as a Treatment Option in Multiple Sclerosis Patients. J Stem Cell Res Ther 1: 102.

7. Fred H. Gage (2000) Mammalian Neural Stem Cells. Science 287: 1433-1438

8. Ghodsizad A, Voelkel T, Moebius JM, Gregoric I, Bordel V, et al. (2010) Biological Similarities Between Mesenchymal Stem Cells (Mscs) and Fibroblasts. J Cytol Histol 1: 101.

9. Porrata LF, Inwards DJ, Ansell SM, Micallef IN, Johnston PB, et al. (2011) Day 15 Peripheral Blood Lymphocyte/monocyte Ratio Postautologous Peripheral 
Citation: Arun Kumar R, Sathish Kumar D, Nishanth T (2011) A Review on Stem cell Research \& Their Role in Various Diseases. J Stem Cell Res Ther 1:112. doi:10.4172/2157-7633.1000112

Page 4 of 5

Hematopoietic Stem Cell Transplantation and Survival in Diffuse Large B-cell Lymphoma. J Stem Cell Res Ther 1: 103.

10. http://www.explorestemcells.co.uk/multipotentstemcells.html

11. Meregalli M, Farini A, Torrente $Y$ (2011) Mesenchymal Stem Cells as Muscle Reservoir. J Stem Cell Res Ther 1: 105.

12. James AT, Joseph Itskovitz-Eldor et al. (1998) Embryonic Stem Cell Lines Derived from Human Blastocysts. Science 282: 1145-1147.

13. Pei M, He F, Wei L (2010) Three-Dimensional Cell Expansion Substrate For Cartilage Tissue Engineering And Regeneration: A Comparison In Decellularized Matrix Deposited By Synovium-Derived Stem Cells And Chondrocytes. J Tissue Sci Eng 2: 104.

14. Suzanne Kadereit Adult Stem Cells. International Society for Stem Cell Research.

15. Mittal R (2011) Mesenchymal Stem Cells: The New Players in the Pathogenesis of Tuberculosis. J Microbial Biochem Technol 3: ii-0.

16. Matthias Stadtfeld, Konrad Hochedlinger (2010) Induced pluripotency: history, mechanisms, and applications. Genes Dev 24: 2239-2263.

17. Ratajczak MZ, Kim CH (2011) Bioactive Sphingolipids and Complement Cascade as New Emerging Regulators of Stem Cell Mobilization and Homing. J Stem Cell Res Ther 1: e102.

18. Stem Cell Research and Applications Monitoring the Frontiers of Biomedical Research (1999) American Association for the Advancement of Science and Institute for Civil Society.

19. Feinberg AP, Ohlsson R, Henikoff S (2006) The Epigenetic Progenitor Origin of Human Cancer. Rev Genet 7: 21-33.

20. Silvani G, Galli D, Benedetti L, Ceccarelli G, Crosetto N, et al. (2011) Peculia Characteristics of Human Mesenchymal Stem Cell Clones Suitable as Tissue Engineering Models. J Tissue Sci Eng 2: 106.

21. Rapp UR, Ceteci F, Schreck R. (2008) Oncogene-Induced Plasticity and Cancer Stem Cells. Cell Cycle 7: 45-51.

22. Miceli V, Cocciadiferro L, Maurizio Z, Kang KS, Trosko JE, et al. (2011) Molecular Profiling of Potential Human Prostate Cancer Stem Cells. J Stem Cell Res Ther S7: 001

23. Allan AL, Vantyghem SA, Tuck AB, Chambers AF. (2007) Tumor Dormancy and Cancer Stem Cells: Implications for the Biology and Treatment of Breast Cancer Metastasis. Breast Dis 26: 87-98.

24. Horie M, Ito A, Kawabe Y, Kamihira M (2011) A Genetically Engineered STO Feeder System Expressing E-Cadherin and Leukemia Inhibitory Factor for Mouse Pluripotent Stem Cell Culture. J Bioprocess Biotechniq S3: 001.

25. Razmkhah M, Jaberipour M, Ghaderi A (2011) Chemokines and Chemokine Receptors Expression in the Adipose Derived Stem Cells (ASCs), Breas Tissues and in Peripheral Blood of Patients with Breast Cancer. J Carcinogene Mutagene 2: 120 .

26. Li F, Tiede B, Massague J, Kang Y (2007) Beyond Tumorigenesis: Cancer Stem Cells in Metastasis. Cell Res 17: 3-14.

27. White HS, Smith L, Gentry T, Balber AE (2011) Mechanisms of Action of Human Aldehyde Dehydrogenase Bright Cells in Therapy of Cardiovascular Diseases: Expression Analysis of Angiogenic Factors and Aldehyde Dehydrogenase Isozymes. J Stem Cell Res Ther S1: 001.

28. Skogseth H, Dybwad M, Flatberg A, Halgunset J (2010) Mature BoneProducing Osteoblasts Alter Gene Expression of Metastasis Related Genes in Prostate Cancer Cells. J Carcinogene Mutagene 1: 111.

29. Bhat W, Abood A, Maraveyas A, Stanley P (2010) Cutaneous Metastasis from Pancreatic Carcinoma- A Case Report and Review. J Clin Exp Dermatol Res 1: 111

30. Pierre M, DeHertogh B, DeMeulder B, Bareke E, Depiereux S, et al. (2011) Enhanced Meta-analysis Highlights Genes Involved in Metastasis from Several Microarray Datasets. J Proteomics Bioinform 4: 036-043.

31. Masayo Y, Kiyonaga F, Koji K, Setsuo H, Tadashi K (2009) The Proteomic Profile of Pancreatic Cancer Cell Lines Corresponding to Carcinogenesis and Metastasis. J Proteomics Bioinform 2: 001-018.

32. Skogseth H, Tvedt KE, Halgunset J (2011) Carcinoma Metastasis - An Approach to Models. J Carcinogene Mutagene 2: 119.
33. Pruneddu S, Piras D, Wijesuriya N, Cerio R (2011) Crohn's Disease and Mucocutaneous Conditions. J Clin Exp Dermatol Res S3: 001.

34. Croker AK, Allan AL (2008) Cancer stem cells: implications for the progression and treatment of metastatic disease. J Cell Mol Med 12: 374-390.

35. Stajner I (2009) Cloudiness and Breast Cancer. J Cancer Sci Ther 1: 034-040.

36. Avramidis D, Cruz M, Sidén A, Tasat DR, Yakisich JS (2009) Regrowth Concentration Zero $\left(\mathrm{RC}_{0}\right)$ as Complementary Endpoint Parameter to Evaluate Compound Candidates During Preclinical Drug Development for Cancer Treatment. J Cancer Sci Ther 1: 019-024.

37. Waterman Ruth S, Betancourt AM (2011) Treating Chronic Pain with Mesenchymal Stem Cells: A Therapeutic Approach Worthy of Continued Investigation. J Stem Cell Res Ther S2: 001

38. María Pérez-Caro, Isidro Sánchez-García (2006) Killing Time for Cancer Stem Cells (CSC): Discovery and Development of Selective CSC Inhibitors. Curren Medicinal Chemistry 13: 1719-1725

39. Mi Z, Guo H, Markovic J, Kuo PC (2009) Characterization of Osteopontin Binding Kinetics In MDA-MB231 Breast and SK-Hep-1 Liver Cancer Cells. J Cancer Sci Ther 1: 047-051.

40. Wang CY, Lee TF, Fang CH (2009) 3D Volumetric Visualization with Automatic Rigid and Deformable Hybrid Image Registration for Adaptive Radiotherapy. J Cancer Sci Ther 1: 041-046.

41. Jamil K, Kumar K, Fatima SH, Rabbani S, Kumar R, et al. (2009) Clinica Studies on Hormonal Status in Breast Cancer and its Impact on Quality of Life (QOL). J Cancer Sci Ther 1: 083-089.

42. Kingsley K, Zuckerman J, Davis M, Matteucci M, Knavel A, etal. (2009) Induction of Differential Growth in vitro by High-risk Human Papillomavirus in Human Breast Cancer Cell Lines is Associated with Caspase Dysregulation. $J$ Cancer Sci Ther 1: 062-071.

43. Nieder C, Spanne O, Bilberg I, Dalhaug A (2010) Primary Tumour Characteristics as Potential Prognostic Factors in Brain Metastases from Breast Cancer. $J$ Cancer Sci Ther 2: 070-073.

44. Jayashankar E, Roshinipaul T (2010) Prognostication of Histomorphological Characteristics in Multiple Myeloma. J Cancer Sci Ther 2: 153-156.

45. Pakseresht S, Ingle GK, Garg S (2011) Quality of Life of Women with Breas Cancer at the Time of Diagnosis in New Delhi. J Cancer Sci Ther 3: 066-069.

46. Naga Deepthi CH, VVL Pavan Kumar A Rameshbabu, Indirapriyadarshini U (2011) Role of Tumor Suppressor Protein p53 in Apoptosis and Cancer Therapy. J Cancer Sci Ther R1: 001.

47. Singh RK, Sudhakar A, Lokeshwar BL (2011) From Normal Cells to Malignancy: Distinct Role of Pro-inflammatory Factors and Cellular RedoxMechanisms. J Cancer Sci Ther 3: 070-075.

48. Nguyen NP (2010) Molecular Biology of Breast Cancer Stem Cells: Potentia Clinical Applications. Cancer Treat Rev 36: 485-491.

49. Harring TR, Kuten DA, Nguyen NT, Goss JA, O'Mahony CA (2011) Orthotopic Liver Transplantation in Patients with Mixed Hepatocellular Carcinoma Cholangiocarcinoma. J Transplant Technol Res 1: 104.

50. Peramo A (2010) Novel Double Lumen Catheter for Drug Delivery at the Skin Catheter Interface. J Tissue Sci Eng 1: 102.

51. Singh V, Sinha RJ, Sankhwar SN, Mehrotra B, Ahmed N, et al. (2010) Squamous Cell Carcinoma of the Kidney - Rarity Redefi ned: Case Series with Review of Literature. J Cancer Sci Ther 2: 082-085.

52. Irioda AC, Zocche L, Souza CMCO, Ferreira RJ, Aliprandini E, et al. (2011) Pap Test as the First Step in Screening Genetic Stability in Cell- Based Therapy. $J$ Stem Cell Res Ther 1: 106

53. Shrihari TG (2011) Cancer Stem Cells - Therapeutic Boon! J Cancer Sci Ther 3: $197-200$.

54. http://www.sciencedaily.com/releases/2011/10/111020094335.htm

55. Ferreira AK, Meneguelo R, Neto SC, Chierice GO, Maria DA (2011) Synthetic Phosphoethanolamine Induces Apoptosis Through Caspase-3 Pathwayby Decreasing Expression of Bax/Bad Protein and Changes Cell Cycle inMelanoma. J Cancer Sci Ther 3: 053-059.

56. Benjamin Beck (2011) A Vascular Niche and a VEGF-Nrp1 Loop Regulate the Initiation and Stemness of Skin Tumours. Nature 478: 399-403. 
Citation: Arun Kumar R, Sathish Kumar D, Nishanth T (2011) A Review on Stem cell Research \& Their Role in Various Diseases. J Stem Cell Res Ther 1:112. doi:10.4172/2157-7633.1000112

Page 5 of 5

57. Liu CY, Chang LC, Yang SW (2011) Metastatic Hepatocellular Carcinoma to the Nasal Cavity: A Case Report and Review of the Literature. J Cancer Sci Ther 3: 081-083.

58. Yu L, Ma J, Ma R, Zhang Y, Zhang X, et al. (2011) Repair of Excitotoxic Neuronal Damage Mediated by Neural Stem Cell Lysates in Adult Mice. J Cell Sci Ther 2: 109.

59. Sell S, Leffert HL (2008) Liver cancer stem cells. J Clin Oncol 26: 2800-2805.

60. Sameh Mikhail, Aiwu Ruth He (2011) Liver Cancer Stem Cells International Int J Hepatol 2011: 1-5.

61. Ponnusamy MP (2010) Stem Cell Research and Cancer Stem Cells. J Tissue Sci Eng 2: 104e.

62. Kivity S, Ben-Haim M, Guranda L, Olchovsky D (2011) Shocking Liver. Rheumatology 1: 103.

63. Vitin AA, Martay K, Vater Y, Dembo G, Maziarz M (2010) Effects of Vasoactive Agents on Blood Loss and Transfusion Requirements During Pre- Reperfusion Stages of the Orthotopic Liver Transplantation. J Anesthe Clinic Res 1: 104.

64. Gayed IW, Wahba H, Wan D, Joseph U, Murthy R (2010) Effect of Y-90 SIRSpheres Therapy for Multiple Liver Metastases in a Variety of Tumors. J Cancer Sci Ther 2: 043-046.

65. Mukherjee S (2009) Antiviral Therapy for Hepatitis B in Preand Post-liver Transplant Patients. J Antivir Antiretrovir 1: 017-027.

66. http://www.sciencedaily.com/releases/2007/03/070327094518.htm

67. Saini A, Devidayal, Verma S, Bhalla AK (2011) Comparative Efficacy of Once Daily Insulin Glargine with Twice Daily NPH Insulin in Children with Type 1 Diabetes. J Diabetes Metab 2: 124.

68. Higuchi C, Tone A, Iseda I, Tsukamoto K, Katayama A, et al. (2010) A Pregnant Patient with Brittle Type 1 Diabetes Successfully Managed by CSII Therapy with Insulin Aspart. J Diabetes Metab 1: 104

69. Ragheb R, Medhat AM (2011) Mechanisms of Fatty Acid-Induced Insulin Resistance in Muscle and Liver. J Diabetes Metab 2: 127

70. Ramachandra S (2011) Do we need yet another Insulin? J Diabet Metabol 2 0e4

71. Ragheb R, Medhat AM (2011) Mechanisms of Fatty Acid-Induced Insulin Resistance in Muscle and Liver. J Diabetes Metab 2: 127

72. Michael JH, Clive HW et al. (2009) Autologous Umbilical Cord Blood Transfusion in Very Young Children with Type 1 Diabetes. Diabetes Care 32: 2041-2046.

73. Joffe B, Distiller L, Landau S, Blacking L, Klisiewicz A (2010) Spectrum of Autoimmune Disorders in Type 1 Diabetes - A Cross-Sectional Clinical Audit. J Diabetes Metab 1: 112.

74. Gao S, Wang X (2009) Predicting Type 1 Diabetes Candidate Genes using Human Protein-Protein Interaction Networks. J Comput Sci Syst Biol 2: 133 146

75. Messripour M (2011) A Novel Enzyme Inhibition Assay for Screening of Type 1 Diabetes Mellitus. J Mol Biomark Diagn 2: 107.

76. Jacobson JD, Midyett LK, Garg U, Sherman AK, Patel C (2011) Biochemical Evidence for Reduced Carnitine Palmitoyl Transferase 1 (CPT-1) Activity in Type 1 Diabetes Mellitus. J Diabetes Metab 2: 144

77. Denis Daneman (2006) Type 1 diabetes. The Lancet 367: 847-858.

78. Wilkinson A, Bian L, Khalil D, Gibbons K, Wong PF, et al. (2011) Type 1 Diabetic Children and Siblings Share a Decrease in Dendritic Cell and Monocyte Numbers but are Differentiated by Expansion of CD4 ${ }^{+} \mathrm{T}$ Cells Expressing IL-17. J Clin Cell Immunol S2: 001.

79. Zhao Y (2011) Autoimmunity and Therapeutic Challenges of Type 1 Diabetes. Translational Medic 1: $104 \mathrm{e}$.

80. Shohta Kodama, Denise L. Faustman (2004) Routes to regenerating islet cells: stem cells and other biological therapies for type 1 diabetes. Pediatr Diabetes 5: $38-44$

81. Gentile P, Scioli MG, Orlandi A, Cervelli V (2011) Review: Application of Platelet-Rich Plasma in Hard Tissue Defects. J Tissue Sci Eng S2: 001.

82. http://www.counterbalance.org/stemcell/nervo-body.html

83. Alain RS, Rivest S (2004) Bone Marrow Stem Cells have the Ability to Populate the Entire Central Nervous System into Fully Differentiated Parenchyma Microglial. The FASEB Journal 18: 998-1000.

84. Valarmathi MT, Fuseler JW (2011) Mammalian Cardiac Muscle Regeneration: Structural and Functional Modulation of Adult Marrow Stromal Stem Cells. Anatom Physiol 1: e102.

85. Lionetti V (2011) How Resident Stem Cells Communicate with Cardiac Cells in Beating Heart? J Stem Cell Res Ther 1: e104.

86. Orlacchio A, Bernardi, G, Martino S (2010) Stem Cells: An Overview of the Current Status of Therapies for Central and Peripheral Nervous System Diseases. Current Medicinal Chemistry 17: 595-608.

87. Patel R, Lomax G (2011) Use of hESC Lines by CIRM Grantees: The Value of Embryonic Stem Cell Research Oversight (ESCRO) Committees. J Stem Cell Res Ther 1: 107.

88. Dvorak CC, Cowan MJ (2008) Hematopoietic Stem Cell Transplantation for Primary Immunodeficiency Disease. Nature 41: 119-126.

89. REBECCA H. B UCKLEY M.D., SHERRIEE HEMATOPOIETIC STEM-CELL TRANSPLANTATION FOR THE TREATMENT OF SEVERE COMBINED IMMUNODEFICIENCYTheNewEnglandJournalofMedicine3407 http://www. nejm.org/doi/pdf/10.1056/NEJM199902183400703

90. Aversa F, Tabilio A, Terenzi A, Velardi A, Falzetti F (1994) Successfu engraftment of T-cell-depleted haploidentical "three-loci" incompatible transplants in leukemia patients by addition of recombinant human granulocyte colony-stimulating factor-mobilized peripheral blood progenitor cells to bone marrow inoculums. Blood 84 3948-3955.

91. Gottlieb H, Klausen TW, Boegsted M, Olsen BS, Lausten GS, et al. (2011) A Clinical Study of Circulating Cellular and Humoral Biomarkers Involved in Bone Regeneration Following Traumatic Lesions. J Stem Cell Res Ther 1: 108.

92. El Tamer MK (2009) Progenitor and Stem Cells for Bone and Cartilage Regeneration. J Tissue Eng Regen Med 3: 327-337.

93. http://www.counterbalance.org/stemcell/disea-body.html

94. Kablan A, Saunders RA, Szkudlarek-Mikho M, Chin JB, Bosio RM, et al. (2010) Prieurianin Causes Weight Loss in Diet-Induced Obese Mice and Inhibits Adipogenesis in Cultured Preadipocytes. J Diabetes Metab 1: 101.

95. Poulose N, Vishnu Prasad CN, Nidhina Haridas PA, Anilkumar G (2011) Ellagic Acid Stimulates Glucose Transport in Adipocytes and Muscles through AMPK Mediated Pathway. J Diabetes Metab 2: 149.

96. Nakazawa K, Shinmura Y, Higuchi A, Sakai Y (2011) Effects of Culture Conditions on a Micropatterned Co-culture of Rat Hepatocytes with $3 T 3$ cells. J Bioprocess Biotechniq S3: 002.

97. Abdel Aziz MT, Wassef MA, Rashed LA, Mhfouz S, Omar N, et al. (2011) Mesenchymal Stem Cells Therapy in Acute Renal Failure: Possible Role of Hepatocyte Growth Factor. J Stem Cell Res Ther 1: 109

98. Mauro Krampera (2006) Mesenchymal Stem Cells for Bone, Cartilage, Tendon and Skeletal Muscle Repair. Bone 39: 678-683.

99. Larsen KH (2010) Bone and Cartilage Repair using Stem Cells. Ugeskr Laeger 172: $2616-2619$

100.Paolo Bianco (2001) Bone Marrow Stromal Stem Cells: Nature, Biology and Potential Applications. Stem Cells 19: 180-192. 